\title{
Estudo da estrutura eletrônica e da geometria da molécula Bromo- chalcona Sulfonamida utilizando Teoria do Funcional da Densidade
}

Fernanda Borges Carvalho $^{1 *}(\mathrm{PG})$, Ademir João Camargo ${ }^{1}(\mathrm{PQ})$ e Solemar Silva Oliveira $^{1}(\mathrm{PQ})$

${ }^{1}$ Grupo de Química Teórica e Estrutural de Anápolis (QTEA) - Campus de Ciências Exatas e Tecnológicas (CCET) - Universidade Estadual de Goiás (UEG)

fborgescarvalho@gmail.com

Palavras-chave: DFT, chalcona, estrutura eletrônica, geometria.

\section{Introdução}

Chalconas representam um grupo de substancias naturais encontradas em flores, frutas, mel e em algumas substancias processadas como chá e vinho (DOMINGUEZ et al., 2001; ELSOHLY et al., 2001). São precursoras dos flavonoides, compostos que apresentam uma grande variedade de atividades de interesses farmacológicos. Quimicamente, esses compostos são chamados de 1,3-difenil-2-propen-1-ona, classificados como cetonas $\alpha, \beta$-insaturadas. A combinação entre carbonila e grupo olefínico cria uma reativa cadeia ceto-etileno que pode propiciar a conjugação entre dois anéis aromáticos. Esta característica lhe fornece potencial biológico e antioxidante. (PATIL, MAHAJAN, KATTI, 2009). Compostos contendo agrupamento sulfonamida, - $\mathrm{SO}_{2} \mathrm{NH}-$, são amplamente utilizados como agentes antibactericidas devido seu baixo custo, baixa toxicidade e grande eficácia contra doenças bacterianas comuns (ÖZBECK, et al., 2007). O grupo sulfonamida ocorre em compostos biologicamente ativos, que inclui drogas antimicrobiais, antitireóidais, antitumorais e antimalarias (OZDEMIR et al., 2010) e também como recentemente descoberto, antidiuréticas e antiglaucomas (KASIMOGULLARI et al., 2010). Devido ao alto potencial antioxidante é de suma importância determinar um estudo da reatividade química desses compostos. Métodos de modelagem molecular são amplamente utilizados na busca da compreensão de estruturas moleculares simples (pequenas moléculas) e complexas (enzimas, proteínas, polímeros). A tecnologia computacional possibilita grandes avanços na obtenção de resultados em estruturas cada vez mais complexas. Dentre os métodos a Teoria do Funcional da Densidade (DFT) apresenta-se como um dos mais importantes e consolidados na literatura.

\section{Metodologia}

No presente trabalho apresentamos um estudo teórico das propriedades geométricas e eletrônicas da Bromo-chalcona Sulfonamida no vácuo utilizando a Teoria do Funcional da Densidade (DFT). Os cálculos de DFT foram realizados usando o nível de teoria em M062-X/6-311++G(2d,p) [REF], determinando as distâncias e os ângulos interatômicos. Analisamos o Mapa de Potencial Eletrostático (MPE) para compor as regiões de maiores e menores densidades eletrônicas. Determinamos os orbitais de fronteira HOMO/LUMO para localizar regiões onde os elétrons de maior e menor energia estão concentrados, podendo assim descrever propriedades quânticas fundamentais no estudo de reações químicas.

\section{Resultados e discussão}

Na Fig. 1 (a), MPE da molécula, as regiões negativas (vermelho, amarelo) representam os sítios de ataque eletrofílicos e as regiões positivas com densidades eletrônicas inferiores (azul, verde) representam os sítios de ataque nucleofílicos. Os 
orbitais HOMO e LUMO (Fig. 1 b e c) da molécula de Bromo-chalcona Sulfonamida, encontram-se envolvendo toda molécula, exceto no anel aromático ligado ao grupo sulfonamida e no grupo metila ligado ao $\mathrm{C} 15$. Sobre a simetria, as ligações dos orbitais HOMO e LUMO (Fig. 01 b e c) são do tipo $\pi$ ligante (pi ligante). Os orbitais HOMO apresentam energia de aproximadamente $-7,69810 \mathrm{eV}$ e os orbitais LUMO $-1,80085 \mathrm{eV}$. O gap HOMO-LUMO foi obtido com DFT usando o funcional M062-X/6$311++\mathrm{G}(2 \mathrm{~d}, \mathrm{p})$, e tem energia de aproximadamente, 5,897 eV que corresponde a um comprimento de onda de $203 \mathrm{~nm}$.
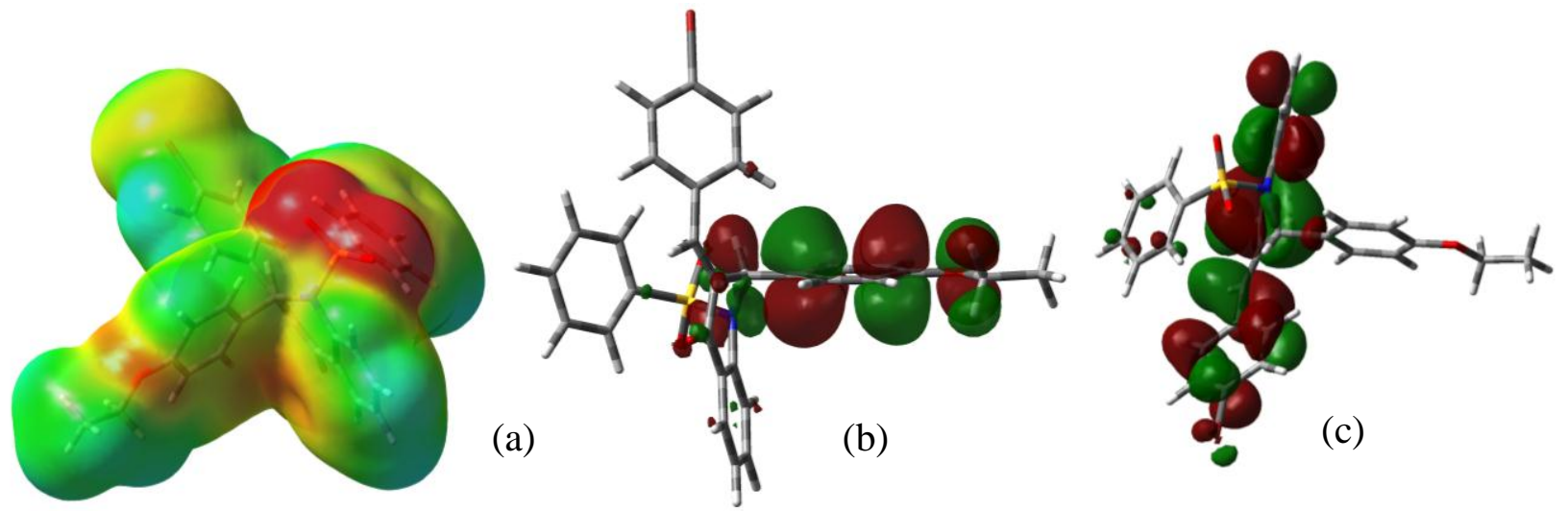

Figura 1. a) MPE, b) HOMO e c) LUMO da molécula de Chalcona.

\section{Conclusão}

Uma análise do Mapa de Potencial mostra claramente que os potenciais negativos eletrostáticos estão nos átomos eletronegativos e os locais de potenciais positivos estão nos átomos de hidrogênio. Essa análise sugere que um estudo com um solvente, como a água, possa fornecer resultados interessantes tal como formação de ligações de hidrogênio.

\section{Agradecimentos}

Agradecimento a CAPES.

\section{Referências}

DOMINGUEZ, J. N.; CHARRIS, J. E.; LOBO, G. Eur. J. Med. Chem. 2001, 36, 555.

ELSOHLY, H. N.; JOSHI, A. S.; NIMROD, A. C.; WALKER, L. A.; CLARK, A. M. Plant Med. 2001, 67,87.

PATIL, C. B.; MAHAJAN, S. K.; KATTI, S. A. J. Pharm. Sci and Res v.3, p.11 $-22,2009$.

ÖZBEK, N.; KARTICIOGLU, H.; KARACAN, N.; BAYKAL, T;“'Synthesis, characterization and antimicrobial activity of new aliphatic sulfonamide". Bioorganic \& Medicinal Chemistry, 2007, v. 15, p. 5105-5109.

OZDEMIR, U. O.; GUVENÇ, P.; SAHIN, E.; HAMURCU, F.; "Synthesis, characterization and antibacterial activity of new sulfonamide derivatives and their nickel (II), cobalt (II) complexes". Inorganica Chimica Acta, 2009, v. 362, p. 2613-2 618.

KASIMOGULlARI, R.; BULBUL, M.; ARSLAN, B. S.; GOKÇE, B.; "Syntheses, characterization and antiglaucoma activity of some novel pyrazole derivatives of 5-amino1,3,4-thiadiazole-2-sulfonamide". European Journal of Medicinal Chemistry, 2010, p.1-5. 